Original Research Article

\title{
To evaluate and compare the efficacy of alcoholic and aqueous extract of Lagenaria siceraria in high fat diet model in wistar rats
}

\author{
Shirish S. Joshi, Firoz M. Tadavi*, Amit R. Birajdar, Snehalata V. Gajbhiye, Anagha A. Shende
}

Department of Pharmacology and Therapeutics, Seth G. S. Medical College and K. E. M. Hospital, Mumbai, Maharashtra, India

Received: 22 July 2017 Accepted: 28 July 2017

\section{*Correspondence to: \\ Dr. Firoz M. Tadavi, \\ Email: drfiroztadavi@ gmail.com}

Copyright: (C) the author(s), publisher and licensee Medip Academy. This is an openaccess article distributed under the terms of the Creative Commons Attribution NonCommercial License, which permits unrestricted noncommercial use, distribution, and reproduction in any medium, provided the original work is properly cited.

\begin{abstract}
Background: Obesity is not only affecting the affluent society but also affecting developing countries like India. The incidence of obesity is rapidly increasing throughout the world. However, the current anti-obesity drugs have numerous limitations.

Methods: The obesity was induced in male wistar rats by giving high-fat diet over 12 weeks. The variables assessed were body weight, abdominal girth, blood triglyceride level, liver weight and fat mass and histopathology of liver. Aqueous and alcoholic extracts of Lagenaria siceraria (200mg/kg and 400mg/kg Doses) were compared to orlistat (treatment control) and high-fat diet group (disease control) for different variables.

Results: Alcoholic and aqueous extracts high dose $(400 \mathrm{mg} / \mathrm{kg})$ of Lagenaria siceraria significantly reduced total body weight $(\mathrm{p}<0.05)$, abdominal girth $(\mathrm{p}$ $<0.05$ ) at week 10 and 12 compared to high fat diet group. Alcoholic extract $(400 \mathrm{mg} / \mathrm{kg})$ significantly reduced total blood triglyceride level $(\mathrm{p}<0.05)$ and total liver weight $(\mathrm{p}<0.05)$ compared to high-fat diet group. None of the study drugs reduced $\%$ liver weight. Alcoholic extract high dose $(p<0.05)$ has shown improvement in histopathological score. Both aqueous and alcoholic extracts have shown reduced fat mass compared to high-fat diet group.

Conclusions: The alcoholic extract $(400 \mathrm{mg} / \mathrm{kg}$ ) of Lagenaria siceraria alleviated high fat diet induced obesity and dyslipidemic changes in rats. The alcoholic extract of Lagenaria siceraria is having better anti-obesity potential than aqueous extract.
\end{abstract}

Keywords: Abdominal girth, Body weight, Blood triglyceride level, Fat mass, Liver weight, Obesity

\section{INTRODUCTION}

Obesity is defined as "A chronic, relapsing, multifactorial, neurobehavioral disease, wherein an increase in body fat promotes adipose tissue dysfunction and an abnormal fat mass physical forces, resulting in adverse metabolic, biomechanical and psychosocial health consequences." by the American Society of Bariatric Physicians.

This emerging problem is not only affecting the affluent society but also affecting developing countries like India. The incidence of obesity is rapidly increasing throughout the world. The obese population is doubled in 2014 since 1980. In 2014, 1.9 billion populations were overweight of age more than 18 years of which over 600 million population were obese. Although obesity is not a major problem in India, urbanization, and westernization of lifestyle is one of the cause for continuously rising incidence of obesity. ${ }^{1}$

The WHO classifies the BMI between $25 \mathrm{~kg} / \mathrm{m}^{2}$ and 30 $\mathrm{kg} / \mathrm{m}^{2}$ as overweight and $>30 \mathrm{~kg} / \mathrm{m} 2$ as obesity. Other than BMI, abdominal girth, waist to hip ratio, these parameters can be used for assessment. The obesity is associated with mortality and morbidity which need to be treated. The mortality in a population with obesity is higher compared 
to normal weight population. ${ }^{2}$ The list of complications includes diabetes, hypertension, cardiovascular disease, renal and hepatic impairment, gastrointestinal complication, metabolic syndrome, osteoarthritis, psychological problem. ${ }^{3}$

Currently, there are three modalities of treatment available. Depending on age, sex, grade of obesity, comorbid condition, and few other factors, it has been treated by lifestyle modification, pharmacotherapy, surgical management. ${ }^{4}$ Few drugs are currently approved by US-FDA, EMA for obesity which are orlistat, lorcaserin, phentermine hydrochloride + topiramate, qsymia, bupropion + naltrexone, contrave, liraglutide. ${ }^{5}$ However, these drugs are to be taken for a long duration to exert their effects and are associated with various lifethreatening side effects. Apart from the mechanism of action, the efficacy of these drugs to reduce weight depends on the subjective determination of person and adherence to treatment. ${ }^{6}$ The bariatric surgery is the last help which medical professional can avail to the patient.

The surgical procedures are associated with complications, and the recurrence of obesity is also common leading to surgical failure. ${ }^{7}$ So, there is a need for a new drug development for the treatment of obesity. Lagenaria siceraria, also called as "Dudhi-Bhopala", has properties like antioxidant, analgesic, anti-inflammatory, hepatoprotective, antibacterial. ${ }^{8}$ Previously its hypolipidemic and anti-triglyceride property has been studied in few animal models. ${ }^{9}$

There are few studies showing the anti-obesity effect of Lagenaria siceraria. However, the model, which researcher have used, does not mimic human obesity. ${ }^{10,11}$ So, there is a need for evaluation of Lagenaria siceraria for its anti-obesity potential using models that mimic human obesity. Various extracts of Lagenaria siceraria like petroleum, alcoholic, chloroform, aqueous, acetone have been studied earlier. Out of which alcoholic and aqueous extracts were found to have lipid-lowering potential. ${ }^{12}$ Hence, we decided to use the alcoholic and aqueous extract of Lagenaria siceraria in the present study.

The present study was planned to evaluate and compare the anti-obesity potential of an alcoholic and aqueous extract of Lagenaria Siceraria in chronic high-fat-dietinduced wistar rat model.

\section{METHODS}

The Committee for the Purpose of Control and Supervision of Experiments on Animals (CPCSEA) guidelines were followed during the entire study.

\section{Experimental animals}

54 adults male Wistar rats (12 for standardization and 42 for study groups) of weight 140-160gm and age 4-6 weeks from the central animal house of our institute were used for the study.

\section{Husbandry conditions}

Animals were housed in separate cages of institutional animal house. The environmental condition was maintained constant throughout the study. The temperature $\left(22 \pm 3^{\circ} \mathrm{C}\right)$, Relative Humidity $(40-60 \%)$ were maintained constant. The animals were kept in housing cage in the ratio of 3 animals/cage. Housing cage's top grill was made up of stainless steel, having separate facilities for food and drinking water in polypropylene bottles with stainless steel sipper tube. Animals received the diet as per the study protocol.

\section{Study drugs}

The alcoholic and aqueous extracts of Lagenaria siceraria were obtained from an Konark Herbals and Health care, Mumbai, India. The doses $200 \mathrm{mg} / \mathrm{kg}$ and $400 \mathrm{mg} / \mathrm{kg}$ used for this study were obtained from the previous studies done for its hypolipidemic potential. ${ }^{12}$ The orlistat was used as in the dose of $50 \mathrm{mg} / \mathrm{kg}$. ${ }^{10}$ It was obtained from Zerofat (Mankind, India). Both drugs were given to animal orally in two divided dose.

\section{Diet}

- Normal diet: Normal daily diet of rat pellet

- High-fat diet: The ingredients of a high-fat diet which was used for obesity induction were Powdered NPD $(365 \mathrm{gm} / \mathrm{kg})$, Lard $(310 \mathrm{gm} / \mathrm{kg})$, Casein $(250 \mathrm{gm} / \mathrm{kg})$, Cholesterol $(10 \mathrm{gm} / \mathrm{kg})$, Vitamins and minerals mix $(60 \mathrm{gm} / \mathrm{kg})$, dl-Methionine $(3 \mathrm{gm} / \mathrm{kg})$, Yeast powder $(1 \mathrm{gm} / \mathrm{kg})$ and Sodium chloride $(1 \mathrm{gm} / \mathrm{kg})$. Specialised diet was given to all rats except normal control group to induce obesity. ${ }^{13}$

42 male Wistar rats were divided into 7 different groups.

Table 1: Study groups.

\begin{tabular}{|lll|}
\hline Group $(\mathbf{n}=\mathbf{6})$ & Diet & $\begin{array}{l}\text { Drug (given daily } \\
\text { orally) }\end{array}$ \\
\hline $\begin{array}{l}\text { Normal } \\
\text { control }\end{array}$ & Normal diet & - \\
\hline $\begin{array}{l}\text { Disease } \\
\text { control }\end{array}$ & High fat diet & - \\
\hline $\begin{array}{l}\text { Positive } \\
\text { control }\end{array}$ & High fat diet & Orlistat $50 \mathrm{mg} / \mathrm{kg} /$ day \\
\hline Test group 1 & High fat diet & $\begin{array}{l}\text { Alcoholic extract } \\
200 \mathrm{mg} / \mathrm{kg} / \mathrm{day}\end{array}$ \\
\hline Test group 2 & High fat diet & $\begin{array}{l}\text { Alcoholic extract } \\
400 \mathrm{mg} / \mathrm{kg} / \mathrm{day}\end{array}$ \\
\hline Test group 3 & High fat diet & $\begin{array}{l}\text { Aqueous extract } \\
200 \mathrm{mg} / \mathrm{kg} / \text { day }\end{array}$ \\
\hline Test group 4 & High fat diet & $\begin{array}{l}\text { Aqueous extract } \\
400 \mathrm{mg} / \mathrm{kg} / \text { day }\end{array}$ \\
\hline
\end{tabular}




\section{Drug administration}

The alcoholic extracts of Lagenaria siceraria $(200 \mathrm{mg} / \mathrm{kg}$ and $400 \mathrm{mg} / \mathrm{kg}$ ) were suspended in carboxymethylcellulose $(0.5 \%)$ whereas aqueous extracts of Lagenaria siceraria $(200 \mathrm{mg} / \mathrm{kg}$ and $400 \mathrm{mg} / \mathrm{kg})$ and orlistat $(50 \mathrm{mg} / \mathrm{kg} /$ day $)$ were suspended in normal saline. Drugs were administered orally using different rat feeding cannulas. The appropriate doses were given over 12 weeks for all groups except normal control which received normal saline.

\section{Experimental procedure}

42 Wistar rats were divided into 7 different groups. All the groups received high-fat diet except normal control group which received normal diet. The procedure was followed for 12 weeks and variables were assessed as per the study protocol.

\section{Variables assessed}

Total body weight, abdominal girth, blood triglyceride level, weight of liver, histopathological assessment of liver (Table 2) and total body fat mass assessment.

Table 2: Histopathological grading of rat liver.

\begin{tabular}{|c|c|c|}
\hline Grade & $\begin{array}{l}\text { Fatty } \\
\text { involvement }\end{array}$ & Description \\
\hline Normal (0) & $0-5 \%$ & Normal \\
\hline Mild (1) & $5-33 \%$ & $\begin{array}{l}\text { Fatty vacuoles in the } \\
\text { hepatocytes with mild } \\
\text { hepatocytes involvement }\end{array}$ \\
\hline $\begin{array}{l}\text { Moderate } \\
\text { (2) }\end{array}$ & $34-66 \%$ & $\begin{array}{l}\text { Central vacuolation with } \\
\text { nucleus shifted to the } \\
\text { periphery with moderate } \\
\text { hepatocytes involvement }\end{array}$ \\
\hline Severe (3) & $\begin{array}{l}67 \text { and } \\
\text { above \% }\end{array}$ & $\begin{array}{l}\text { Extensive hepatocytes } \\
\text { involvement with fatty } \\
\text { globules or fatty cyst } \\
\text { formation }\end{array}$ \\
\hline
\end{tabular}

\section{Statistical analysis}

The results were expressed as mean \pm SD. The level of significance ( $\mathrm{p}$-value) for each comparison in the analysis was calculated at 0.05 .

In Phase, I, the parametric data between two groups was compared using unpaired t-test while the non-parametric data between two groups was compared using MannWhitney test.

In Phase II, the parametric data between seven groups was compared using one-way-ANOVA test followed by post hoc Tukey's test while non-parametric data between seven groups was analysed using Kruskal-Wallis test. The statistical analysis was performed using Graph-Pad Instat software version 3.3.

\section{RESULTS}

High-fat diet group showed significant increase in average total body weight and abdominal girth at 8 weeks and 12 weeks compared to normal diet group (animals fed with rat pellet). High-fat diet group showed significant increase in average triglyceride level at 6 weeks and 12 weeks compared to normal diet group. High-fat diet group demonstrated increase in average liver weight, average \% liver weight, average fat mass and increased median histopathological grading compared to normal diet group at the end of 12 weeks.

\section{Total body weight}

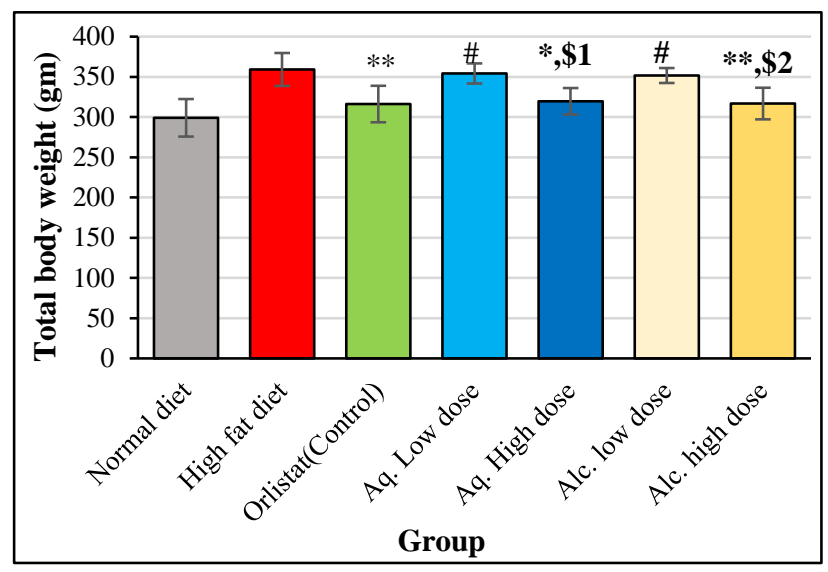

Total body weight expressed as mean $\pm \mathrm{SD}(\mathrm{cm})$; One-way ANOVA followed by post hoc analysis; $* \mathrm{p}<0.05, * * \mathrm{p}<0.01 \mathrm{v} / \mathrm{s}$ High fat diet; $\# \mathrm{p}<0.05 \mathrm{v} / \mathrm{s}$ orlistat; $\$ 1 \mathrm{p}<0.05 \mathrm{v} / \mathrm{s}$ aq. low dose; $\$ 2 \mathrm{p}<0.05 \mathrm{v} / \mathrm{s}$ alc. low dose

Figure 1: Comparison of average total body weight at week 10 .

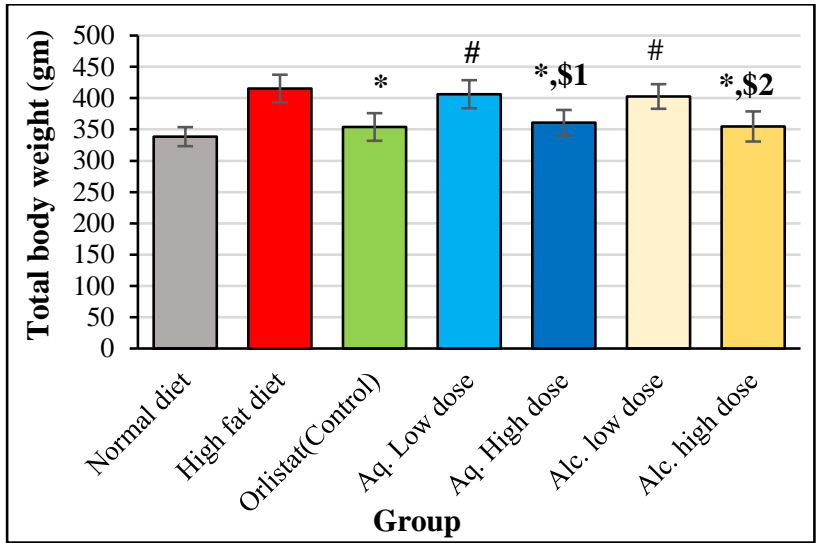

Total body weight expressed as mean \pm SD (cm); One-way ANOVA followed by post hoc analysis; $* \mathrm{p}<0.01 \mathrm{v} / \mathrm{s}$ High fat diet; $\# \mathrm{p}<0.01 \mathrm{v} / \mathrm{s}$ orlistat; $\$ 1 \mathrm{p}<0.05 \mathrm{v} / \mathrm{s}$ aq. low dose; $\$ 2 \mathrm{p}<0.01$ $\mathrm{v} / \mathrm{s}$ alc. low dose

Figure 2: Comparison of average total body weight at week 12.

At week 8, the total body weight has not shown significant difference in two groups. At week 10, orlistat $(\mathrm{p}<0.01)$, 
high dose alcoholic ( $\mathrm{p}<0.01)$ and aqueous extract ( $\mathrm{p}$ $<0.05$ ) showed significant reduction as compared to disease control in average total body weight. The reduction in total body weight achieved with orlistat was comparable to high dose alcoholic and aqueous extract.

At week 12, Orlistat ( $\mathrm{p}<0.01)$, aqueous high dose ( $\mathrm{p}$ $<0.01$ ), alcoholic high dose group ( $\mathrm{p}<0.01$ ) showed significantly reduced average weight compared to high-fat diet group. The average weight of aqueous high dose and alcoholic the high dose group was comparable to orlistat group.

\section{Abdominal girth}

At week 8 , the average abdominal girth has not shown significant difference in two groups.

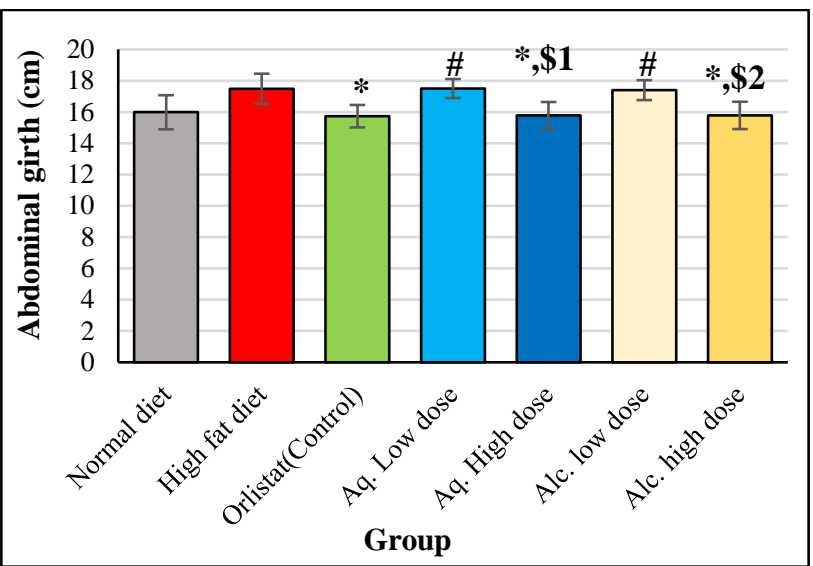

Abdominal girth expressed as mean \pm SD (cm); One-way ANOVA followed by post hoc analysis; ${ }^{*} \mathrm{p}<0.05 \mathrm{v} / \mathrm{s}$ High fat diet; \#p $<0.05$ v/s orlistat; $\$ 1 \mathrm{p}<0.05 \mathrm{v} / \mathrm{s}$ aq. low dose; $\$ 2 \mathrm{p}<0.05$ $\mathrm{v} / \mathrm{s}$ alc. low dose

Figure 3: Comparison of average abdominal girth at week 10.

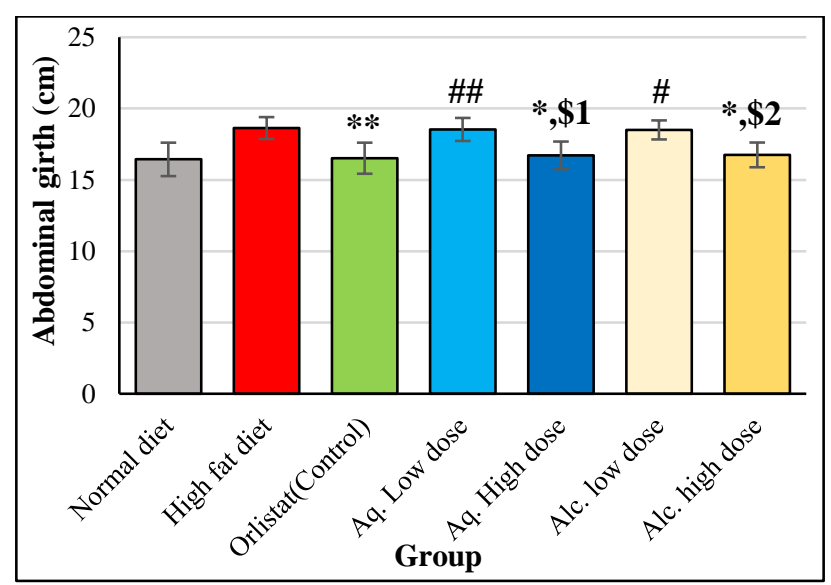

Abdominal girth expressed as mean $\pm \mathrm{SD}(\mathrm{cm})$; One-way ANOVA followed by post hoc analysis; ${ }^{*} \mathrm{p}<0.05, * * \mathrm{p}<0.01 \mathrm{v} / \mathrm{s}$ High fat diet; \#p<0.05,\#\#p<0.01 v/s orlistat; $\$ 1 \mathrm{p}<0.05 \mathrm{v} / \mathrm{s}$ aq. low dose; $\$ 2 \mathrm{p}<0.05 \mathrm{v} / \mathrm{s}$ alc. low dose

Figure 4: Comparison of average abdominal girth at week 12 .
At week 10, Orlistat ( $\mathrm{p}<0.05)$, aqueous extract high dose $(\mathrm{p}<0.05)$, alcoholic extract high dose $(\mathrm{p}<0.05)$ showed significantly reduced abdominal girth compared to highfat diet group. Aqueous high dose and alcoholic the highdose group did not differ statistically from orlistat in average abdominal girth.

At week 12, Orlistat $(\mathrm{p}<0.01)$, aqueous extract high dose $(\mathrm{p}<0.05)$, alcoholic extract high dose group $(\mathrm{p}<0.05)$ showed reduced average abdominal girth compared to high-fat diet group. The average abdominal girth of orlistat was comparable with aqueous high dose and alcoholic high dose group.

\section{Blood triglyceride level}

At week 6, Orlistat $(\mathrm{p}<0.01)$ and alcoholic extract high dose $(\mathrm{p}<0.05)$ showed significant reduced average blood triglyceride level compared to high-fat diet group. At week 12 , Orlistat $(\mathrm{p}<0.05)$ and alcoholic extract high dose $(\mathrm{p}$ $<0.05$ ) showed significantly reduced blood triglyceride level compared to high-fat diet group. High dose of both aqueous and alcoholic extracts showed comparable average blood triglyceride level when compared with orlistat group.

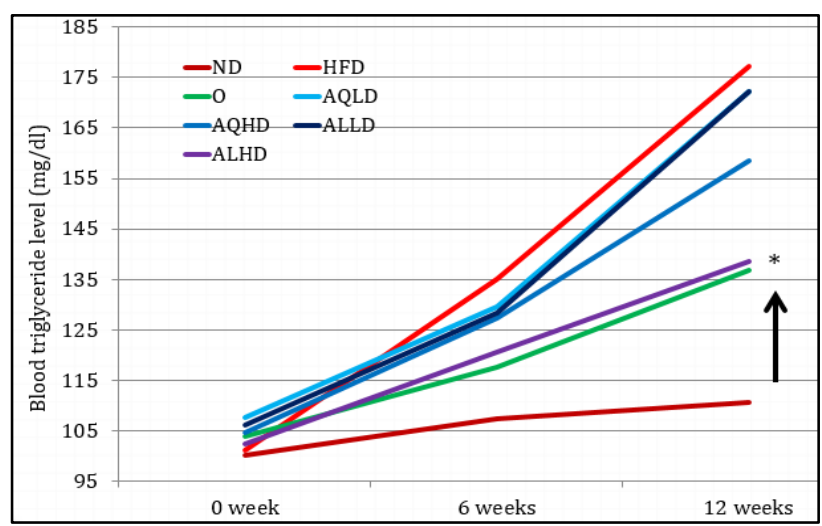

ND - Normal diet, HFD - High fat diet, O - Orlistat, AQLD Aqueous low dose

AQHD - Aqueous high dose, ALLD - Alcoholic low dose, ALHD - Alcoholic high dose

Figure 5: Comparison of average blood triglyceride level at week 6 and week 12 .

\section{Total liver weight}

At the end of 12 weeks, Orlistat ( $p<0.01$ ), alcoholic extract high dose group $(\mathrm{p}<0.05)$ showed a significant reduction in average total liver weight compared to high-fat diet group. The average liver weight of alcoholic extract high dose and orlistat group were comparable.

\section{\% weight of liver compares to total body weight}

Only orlistat group $(\mathrm{p}<0.01)$ showed significant reduction in average \% weight of liver compared to high-fat diet 
group. However, all other groups did not show significant difference compared with high-fat diet group.

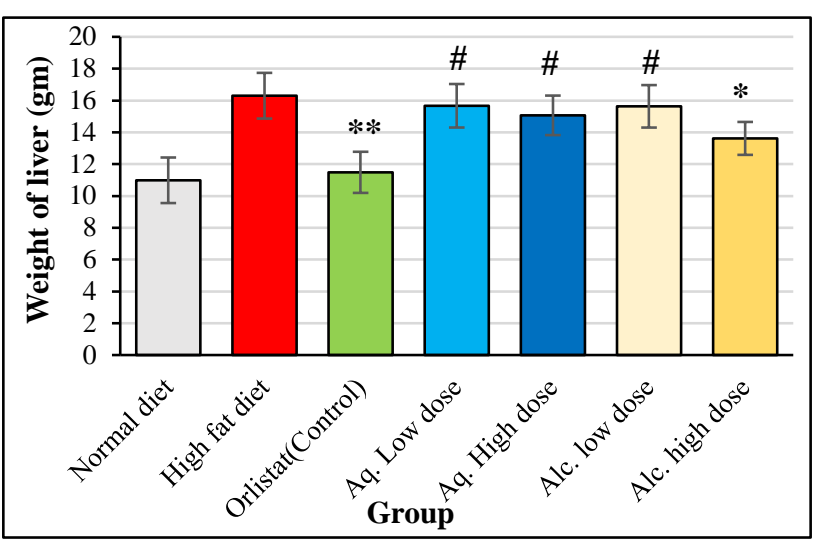

Total liver weight expressed as mean \pm SD (gm); One-way ANOVA followed by post hoc analysis; $* \mathrm{p}<0.05$, **p $<0.01 \mathrm{v} / \mathrm{s}$ High-fat diet; $\# \mathrm{p}<0.01 \mathrm{v} / \mathrm{s}$ orlistat

Figure 6: Comparison of average liver weight.

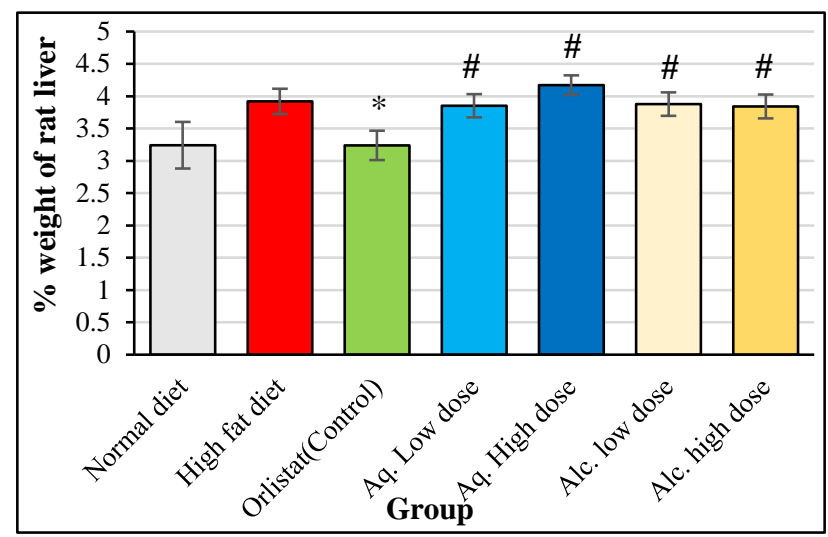

$\%$ Weight of liver compared to body weight expressed as mean $\pm \mathrm{SD}(\%)$; One-way ANOVA followed by post hoc analysis; $* \mathrm{p}<0.01 \mathrm{v} / \mathrm{s}$ High-fat diet; $\# \mathrm{p}<0.01 \mathrm{v} / \mathrm{s}$ orlistat

Figure 7: Comparison of average \% liver weight.

\section{Histopathological assessment}

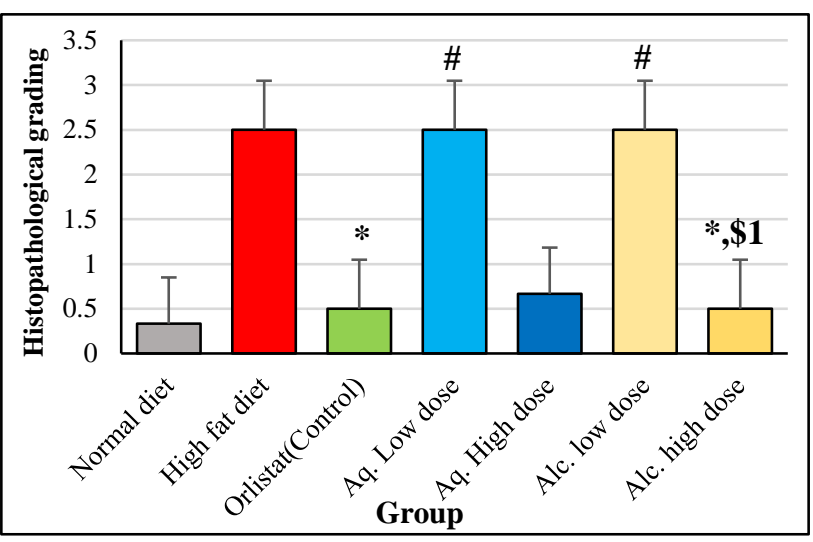

Histopathological score of liver-expressed as mean+SD (grade); Kruskal-Wallis test followed by post hoc analysis; *p $<0.05 \mathrm{v} / \mathrm{s}$ High fat diet; $\# \mathrm{p}<0.05 \mathrm{v} / \mathrm{s}$ orlistat; $\$ 1 \mathrm{p}<0.05 \mathrm{v} / \mathrm{s}$ alc. low dose

Figure 8: Comparison of histopathological score.
Orlistat ( $\mathrm{p}<0.05$ ), alcoholic extract high dose group ( $\mathrm{p}$ $<0.05$ ) showed a significant reduction in median histopathological score compared to high-fat diet group. However, all other study drugs except alcoholic extract high dose did not show significant difference compared with high-fat diet group.

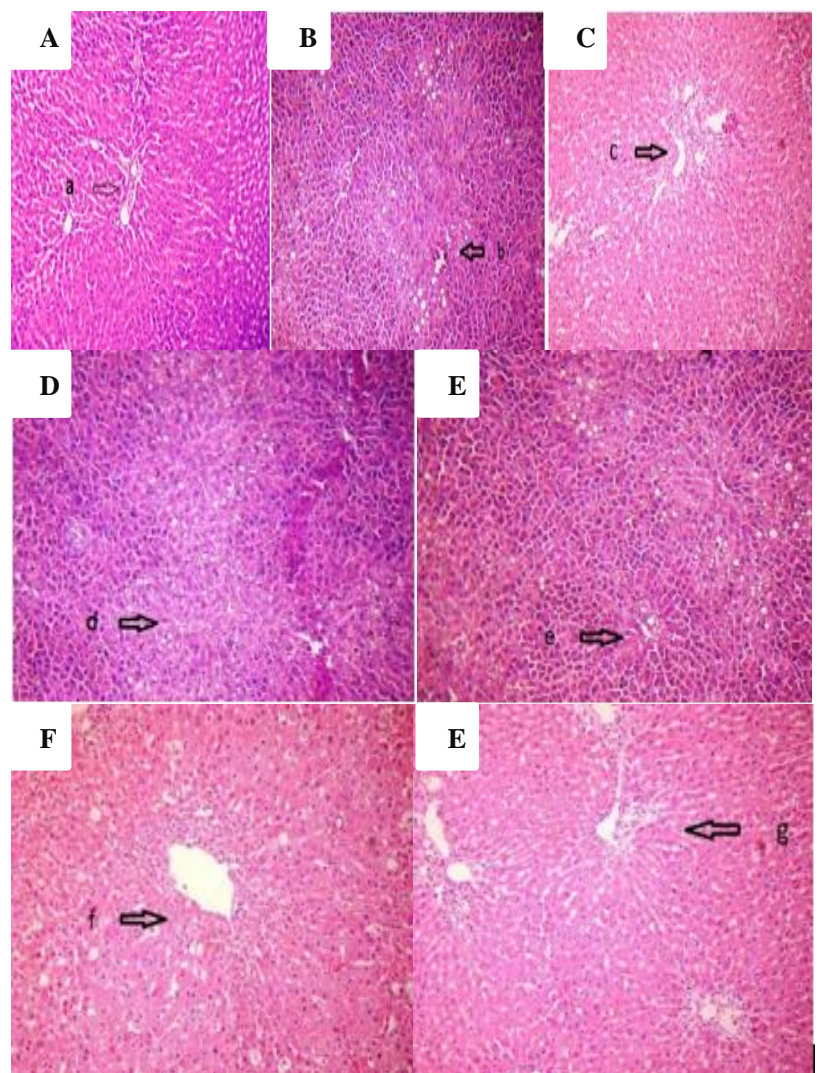

Histopathological changes in different drug dose. 'c' and 'e' are showing near normal architecture whereas others are showing fatty changes. The tissues were stained with $\mathrm{H}$ and $\mathrm{E}$ and photographs were taken on $100 \times$ magnification.

Figure 9: Histopathological examination of liver tissue in rats of different group. Arrow mark is indicative of histological changes in liver: A) Normal diet group Normal liver structure and architecture, B) High fat diet group - Fatty changes in liver and disruption of architecture, C) Orlistat, D) Aqueous low dose, E)

Aqueous high dose, F) Alcoholic low dose, G) Alcoholic high dose.

\section{Fat mass measurement}

Orlistat ( $\mathrm{p}<0.01)$, aqueous extract high dose group (p $<0.05$ ), alcoholic extract high dose group ( $p<0.01)$ has shown a significant reduction in average fat mass compared to high-fat diet group. The average fat mass of aqueous high dose and alcoholic the high dose group was comparable to orlistat group.

\section{DISCUSSION}

The alcoholic extract $(400 \mathrm{mg} / \mathrm{kg})$ of Lagenaria siceraria alleviated high fat diet induced obesity and dyslipidemic 
changes in rats by reducing body weight, abdominal girth, fat mass, liver weight, inducing favorable lipid profile and liver histology. The alcoholic extract of Lagenaria siceraria is having better anti-obesity potential than aqueous extract.

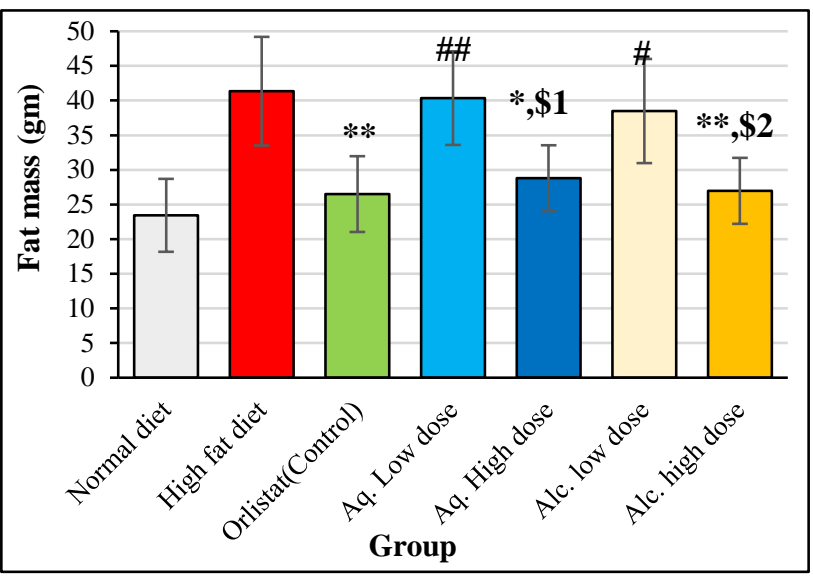

Total fat mass expressed as mean \pm SD; One-way ANOVA followed by post hoc analysis; ${ }^{*} \mathrm{p}<0.05, * * \mathrm{p}<0.01 \mathrm{v} / \mathrm{s}$ High fat diet; \#p $<0.05, \# \# \mathrm{p}<0.01 \mathrm{v} / \mathrm{s}$ orlistat; $\$ 1 \mathrm{p}<0.05 \mathrm{v} / \mathrm{s}$ aq. low dose; $\$ 2 \mathrm{p}<0.05 \mathrm{v} / \mathrm{s}$ alc. low dose

\section{Figure 10: Comparison of average fat mass of Wistar rat.}

Current management of obesity includes lifestyle modifications, pharmacotherapy and surgical management. The aim of pharmacotherapy is either to reduce appetite and/or inhibit absorption and therapy need to be given for longer duration. Based on this, drugs have been approved by various drugs regulatory authorities throughout the world. However, the drugs at present, are not efficacious to reduce weight if used for the short term while on long term or chronic use, the probability of psychiatric and cardiac side effects increase. Pharmacotherapy with present drugs should be allowed after safety and risk assessment for the individual patient. ${ }^{14}$ Thus, there is need for safe and efficacious alternative for chronic weight management.

In quest of a new drug, different animal models have been studied to emulate human obesity for developing an effective treatment for the same. Among the animal models, rats fed on a high-fat diet (HFD) is considered as most useful one. ${ }^{15}$ The physiological mechanisms involved in this model are overconsumption of dietary fat that results in higher quantity of fat getting stored in the body as well as the alterations in the hormones involved in energy balance. This leads to hyperleptinemia, hyperinsulinemia and lowered suppression of ghrelin secretion. This model shows almost all the features of obesity which are distinctly linked to human obesity such as visceral adiposity, hyperglycemia, dyslipidemia, hyperinsulinemia and hepatic steatosis. ${ }^{15}$ Other models of obesity like a genetic model, hypothalamic model, the drug induced model, surgical model is there but the prevalence of obesity by virtue of these mechanisms is very rare.
Thus, we decide to choose HFD model of obesity. Rat is commonly used in HFD obesity model due to its common biological pathway of energy homeostasis. During initial preclinical studies, the male was preferred over the female to avoid interference of estrus cycle. ${ }^{16}$ Majority of effects induced by high fat diet are present in both Wistar and Sprague-Dawley rat. However, studies have shown that these effects are more consistent and seen much earlier in male Wistar rat compared to Sprague-Dawley rat. Thus, in the present study, we have used male Wistar rat as an experimental animal. ${ }^{17}$ Various variables are being used to evaluate the antiobesity potential of the compound. Total body weight and abdominal girth are most commonly used variables in the animal study. ${ }^{10,18}$ The duration of assessment of total body weight and abdominal girth was every 2 weeks and at 6 and 12 weeks for triglyceride level. The duration of 12 weeks was chosen as previous studies have shown increase in body weight, abdominal girth, fat mass and alteration of lipid profile with high fat diet fed over a period of 12 weeks. ${ }^{19}$ The alteration of lipid profile might be due to activation of lipases, intestinal fat absorption, and lipolysis.

High dose alcohol and aqueous extracts have shown reduction in body weight and abdominal girth at week 10 and 12. This reduction is comparable with orlistat. The mechanism that resulted in reduction in body weight and abdominal girth may be attributed to inhibition of fat absorption through GIT. ${ }^{20}$

Only high dose $(400 \mathrm{mg} / \mathrm{kg})$ alcoholic extract was found to reduce blood triglyceride level. Oral administration of Lagenaria siceraria significantly inhibits the activation of lipase and thereby prevents absorption of triglyceride. The suppression of serum triglyceride may result from inhibition of the absorption of fat and cholesterol by blocking the activity of lipase. Our results are in line with previous work done by Nainwal et al, which evaluated the fruit extract of Lagenaria siceraria for its antilipidemic potential in atherogenic diet model in rat. ${ }^{18}$ In another study, Nadeem et al, studied the effect of Lagenaria siceraria fruit extract for 30 days in HFD wistar rat model and showed a significant reduction in body weight, blood glucose, total cholesterol, and triglyceride level. ${ }^{10}$ Ghule et al, studied 4 different extracts of Lagenaria siceraria in triton induced hyperlipidemia model of rats and result showed that hypolipidemic potency of the alcoholic extract is far better than aqueous and ether extract. ${ }^{12}$ Later, Ghule et al, specifically studied alcoholic extract of Lagenaria siceraria in HFD wistar rat and confirmed the significant reduction in triglyceride level at the end of 4 weeks. ${ }^{21}$

In our study, the high dose $(400 \mathrm{mg} / \mathrm{kg})$ alcoholic extract showed reduction in liver weight. However, none of the extracts showed significant reduction in the $\%$ liver weight. Previous studies have shown that reduction in liver weight correlates with anti-obesity potential. ${ }^{22}$ In few studies, instead of liver weight, the more sensitive \% liver weight reduction parameter was used. We did not find 
reduction in \% liver weight as HFD is not a good model to induce changes in liver and the effect of the extract on liver metabolism is negligible. Previous literature also showed that cafeteria diet is much better to study liver changes in obese rat than HFD. ${ }^{23}$

In the present study, histopathological damage of liver is assessed by Brunt scoring system. ${ }^{24}$ The histopathological changes are regressed only by a high dose of alcoholic extract $(400 \mathrm{mg} / \mathrm{kg})$. This change could be related to antioxidant and free radical scavenging property of Lagenaria siceraria. Phytochemical screening of fruit has shown the presence of flavonoids, saponins, steroids and polyphenolic compounds in the extract. ${ }^{25}$ These antioxidants are very important to prevent oxidative damage to liver cells and consequently prevent histopathological changes. One of the previous studies have shown that antioxidant and free radical scavenging property is present in only alcoholic, hydroalcoholic and acetone extract but absent in ether, aqueous, benzene, chloroform extracts of Lagenaria siceraria. ${ }^{26}$

Along with dyslipidemic changes in plasma and increased liver triglyceride, the excess triglyceride accumulates in different body location in the form of fat mass. This fat mass was assessed in the present study and was found that both higher dose extracts $(400 \mathrm{mg} / \mathrm{kg})$ significantly reduced fat mass. Previous evidence have concluded that presence of phytochemicals from plant extracts such as flavonoids, polyphenol, saponin, steroids reduces the level of adipose tissue by decreasing the level of triglycerol and inducing apoptosis. ${ }^{27}$ Apart from this, the effect may be contributed to inhibition of fat absorption which subsequently decreases the adipose tissue hypertrophy and hyperplasia.

Our study has few limitations. We did not assess the change in the average amount of rat diet. So, whether the antiobesity action is due to the hypothalamic effect of Lagenaria siceraria which consecutively reduces feeding behavior or only by inhibiting fat absorption through GIT or both, is still inconclusive. The method for fat mass assessment in the present study is very crude one. MicroCT Scan is used as a most sensitive to detect adiposity in the rat, however due to feasibility we could not perform the same. ${ }^{28}$ The mechanism of action postulated for Lagenaria siceraria is through inhibition of lipase enzyme. ${ }^{29}$ Thus, evaluation of fecal lipid level and the fat marker would have been confirmed our results. However, we have not performed these tests. Also, the measurement of serum cholesterol (HDL and LDL), blood glucose, TNF- $\alpha$ would have strengthened the evidence of our study.

Though this study we demonstrate the anti-obesity effect of Lagenaria siceraria which could possibly be attributed to diverse phytochemicals. However, it is not clear which of the active phytochemical is responsible for this effect. Hence, further work is needed with individual phytochemical to establish the mechanisms explaining the effect.

\section{CONCLUSION}

Based on physiological, biochemical and histological analyses, we have demonstrated that alcoholic extract (400mg/kg) of Lagenaria siceraria alleviated high fat diet induced obesity and dyslipidemic changes in rats by reducing body weight, abdominal girth, fat mass, liver weight, normalizing lipid variables and liver histology. The alcoholic extract of Lagenaria siceraria is having better anti-obesity potential than aqueous extract. This may suggest that it has therapeutic potential to curb obesity and the pathologies linked to obesity. However, further investigations are needed to assess the phytochemicals from alcoholic extract responsible for weight reduction.

Funding: Funding sources from Diamond Jubilee Society Trust, Seth G. S. Medical College and K. E. M. Hospital, Mumbai, Maharashtra, India and Research Society, Seth G. S. Medical College and K. E. M. Hospital, Mumbai, Maharashtra, India

Conflict of interest: None declared

Ethical approval: The study was approved by the Institutional Animal Ethics Committee (AEC/11/2014)

\section{REFERENCES}

1. WHO | Obesity and overweight; 2016. Available at: http://www.who.int/mediacentre/factsheets/fs311/en/. Accessed 20 June 2017.

2. Abdullah A, Wolfe R, Stoelwinder J, de Courten M, Stevenson C, Walls H, et al. The number of years lived with obesity and the risk of all-cause and causespecific mortality. Int J of Epi. 2011;40(4):985-96.

3. Segula D. Complications of obesity in adults: A short review of the literature. Malawi Medical Journal: The J of Med A of Mal. 2014;26(1):20-4.

4. Misra A, Chowbey P, Makkar B, Vikram N, Wasir J, Chadha D. Concensus Group. Consensus statement for diagnosis of obesity, abdominal obesity and the metabolic syndrome for Asian Indians and recommendations for physical activity, medical and surgical management. The Journal of the Association of Physicians of India. 2009;57:163-70.

5. Halford J, Boyland E, Blundell J, Kirkham T, Harrold J. Pharmacological management of appetite expression in obesity. Nature Reviews Endocrinology. 2010;6(5):255-69.

6. Kim G, Lin J, Blomain E, Waldman S. Anti-Obesity Pharmacotherapy: New Drugs and Emerging Targets. Clinical Pharmacology and Therapeutics. 2014;95(1):53-66.

7. Lara M, Kothari S, Sugerman H. Surgical management of obesity: a review of the evidence relating to the health benefits and risks. Treatments in Endocrinology. 2005;4(1):55-64.

8. Prajapati R, Kalariya M, Parmar S, Sheth N. Phytochemical and pharmacological review of Lagenaria sicereria. Journal of Ayurveda and Integrative Medicine. 2010;1(4):266-72. 
9. Aslam M, Najam R. Hypolipidemic and AntiAtherogenic Activity of Aqueous Extract of Leaves of Lagenaria Siceraria in Wistar Rats. Journal of Natural Remedies. 2014;14(1):52-7.

10. Nadeem S, Dhore P, Quazi M, Pawar S, Raj N. Lagenaria siceraria fruit extract ameliorate fat amassment and serum TNF-in high-fat diet-induced obese rats. Asian Pacific Journal of Tropical Medicine. 2012;5(9):698-702.

11. Maqsood M, Ahmed D, Atique I, Malik W. Lipase inhibitory activity of Lagenaria siceraria fruit as a strategy to treat obesity. Asian Pac J Trop Med. 2017;10(3):305-10.

12. Ghule B, Ghante M, Saoji A, Yeole P. Hypolipidemic and antihyperlipidemic effects of Lagenaria siceraria (Mol.) fruit extracts. Indian Journal of Experimental Biology. 2006;44(11):905-9.

13. Srinivasan K, Viswanad B, Asrat L, Kaul C, Ramarao P. Combination of high-fat diet-fed and low-dose streptozotocin-treated rat: A model for type 2 diabetes and pharmacological screening. Pharmacological Research. 2005;52(4):313-20.

14. Hainer V, Toplak H, Mitrakou A. Treatment modalities of obesity: what fits whom? Diabetes Care. 2008;31(2):269-77.

15. Vickers S, Jackson H, Cheetham S. The utility of animal models to evaluate novel anti-obesity agents. British Journal of Pharmacology. 2011;164(4):124862.

16. Amengual E, Lladó I, Gianotti M, Proenza A. Sex differences in the effect of high-fat diet feeding on rat white adipose tissue mitochondrial function and insulin sensitivity. Metabolism: Clinical and Experimental. 2012;61(8):1108-17.

17. Marques C, Meireles M, Norberto S, Leite J, Freitas J, Pestana D, et al. High-fat diet-induced obesity Rat model: a comparison between Wistar and SpragueDawley Rat. Adipocyte. 2015;5(7):1-11.

18. Nainwal P, Nanda D, Tripathi S. Reduction in Blood Cholestrol Level Using the Hydroalcoholic Extract of Fruits of Lagenaria siceraria. International Journal of Research in Pharmaceutical and Biomedical Sciences. 2011;2(1):110-3.

19. Yang M, Chan K, Lee Y, Chang X, Wu C, Wang C. Sechium edule shoot extracts and active components improve obesity and a fatty liver that involved reducing hepatic lipogenesis and adipogenesis in highfat-diet-fed rats. Journal of Agricultural and Food Chemistry. 2015;63(18):4587-96.

20. Kamalakkannan S, Rajendran R, Venkatesh RV, Clayton P, Akbarsha MA. Antiobesogenic and antiatherosclerotic properties of Caralluma fimbriata extract. J of Nutrition and Metabolism. 2010 Dec $28 ; 2010$.

21. Ghule B, Ghante M, Saoji A, Yeole P. Antihyperlipidemic effect of the methanolic extract from Lagenaria siceraria Stand. fruit in hyperlipidemic rats. $\mathrm{J}$ of Ethnopharmacology. 2009;124(2):333-7.

22. Olek R, Ziolkowski W, Flis D, Fedeli D, Fiorini D, Wierzba $T$, et al. The effect of ethyl pyruvate supplementation on rat fatty liver induced by a highfat diet. J Nutr Sci Vitaminol. 2013;59(3):232-7.

23. Sampey B, Vanhoose A, Winfield H, Freemerman A, Muehlbauer M, Fueger P, et al. Cafeteria diet is a robust model of human metabolic syndrome with liver and adipose inflammation: comparison to high-fat diet. Obesity (Silver Spring, Md.). 2011;19(6):110917.

24. Brunt E, Tiniakos D. Histopathology of nonalcoholic fatty liver disease. World Journal of Gastroenterology. 2010;16(42):5286-96.

25. Ahmed D, Fatima M, Saeed S. Phenolic and flavonoid contents and anti-oxidative potential of epicarp and mesocarp of Lagenaria siceraria fruit: A comparative study. Asian Pacific Journal of Tropical Medicine. 2014;7(S1):S249-55.

26. Deshpande J, Mishra M, Meghre V, Wadodkar S, Dorle A. Free radical scavenging activity of lagenaria siceraria (Mol.) Standl. Fruit. Indian Jo of Natural Products and Resources 2007;6(2):127-30.

27. Gutiérrez-Salmeán G, Ortiz-Vilchis P, Vacaseydel C, Garduño-Siciliano L, Chamorro-Cevallos G, Meaney E, et al. Effects of (-)-epicatechin on a diet-induced rat model of cardiometabolic risk factors. European Journal of Pharmacology. 2014;728(1):24-30.

28. Judex S, Luu Y, Ozcivici E. Adler B, Lublinski S, Rubin C. Quantification of Adiposity in Small Rodents using Micro-CT, Methods. 2010;50(1):24351.

29. Wang Y, Wang J, Yanagita R, Liu C, Hu X, Dong P, et al. Effects of two sulfated triterpene saponins echinoside $\mathrm{A}$ and holothurin $\mathrm{A}$ on the inhibition of dietary fat absorption and obesity reduction. Bioscience, Biotechnology, and Biochemistry. 2014;78(1):139-46.

Cite this article as: Joshi SS, Tadavi FM, Birajdar AR, Gajbhiye SV, Shende AA. To evaluate and compare the efficacy of alcoholic and aqueous extract of Lagenaria siceraria in high fat diet model in wistar rats. Int $\mathrm{J}$ Basic Clin Pharmacol 2017;6:2117-24. 